\title{
Tuberculous Pyopneumothorax as A Complication of Inadequate Treatment in Active Pulmonary Tuberculosis: A Case Report
}

\author{
Daniel Maranatha* (D) and Samsul Bahri \\ Department of Pulmonology and Respiratory Medicine, Faculty of Medicine, Airlangga University - \\ Dr. Soetomo General Academic Hospital, Surabaya 60286, Indonesia.
}

\begin{abstract}
Various factors in tuberculosis (TB) management can cause inadequate treatment or failures in therapy. Drug-induced hepatotoxicity is one of the adverse effects of anti-tuberculosis drugs (ATD), which can reduce the effectiveness of treatment. Pneumothorax, empyema, and pyopneumothorax are complications of pulmonary tuberculosis, whilst infrequent but leading to significant morbidity and mortality. A 24-year-old woman came with the main complaint of shortness of breath. She was referred with pulmonary TB, right-side pneumothorax, and drug-induced liver injury (DILI) related to ATD. After DILI resolved, standard 6-month treatment (2HRZE/4HR) was continued, but the patient experienced nausea, vomiting, icteric sclera, and an elevation of transaminases. The combination of ATD was discontinued, just ethambutol and streptomycin were given until the transaminases improved. Afterward, the patient was given isoniazid (H), rifampicin (R), and ethambutol (E). The following week an elevation of transaminases was seen, all ATD was discontinued and the patient was given hepatoprotective therapy. After DILI resolved, a regimen of isoniazid (H), pyrazinamide (Z), ethambutol (E) were given. Later in the follow-up chest $X$-ray, there was worsening homogeneous opacity in the right hemithorax. Pus was observed on thoracentesis and chest tube was inserted for drainage. We presented a case of a pulmonary TB patient with hydropneumothorax having episodes of drug-induced liver injury. The hepatotoxicity related to ATD leads to repetitive discontinuation and change of regiment, resulting in inadequate therapy in the intensive phase of tuberculosis therapy which resulted in pyopneumothorax.
\end{abstract}

Keywords: Pneumothorax, empyema, tuberculosis, drug-induced liver injury

\footnotetext{
*Correspondence: daniel-maranatha@fk.unair.ac.id; +6231-5501656
}

(Received: February 12, 2020; accepted: June 24, 2020)

Citation: Maranatha D, Bahri S. Tuberculous Pyopneumothorax as A Complication of Inadequate Treatment in Active Pulmonary Tuberculosis: A Case Report. J Pure Appl Microbiol. 2020;14(2):1115-1120. doi: 10.22207/JPAM.14.2.05

(C) The Author(s) 2020. Open Access. This article is distributed under the terms of the Creative Commons Attribution 4.0 International License which permits unrestricted use, sharing, distribution, and reproduction in any medium, provided you give appropriate credit to the original author(s) and the source, provide a link to the Creative Commons license, and indicate if changes were made. 


\section{INTRODUCTION}

Pneumothorax, empyema, and pyopneumothorax are complications of pulmonary tuberculosis (TB), whilst infrequent but leading to significant morbidity and mortality ${ }^{1,2}$. Tuberculous pleural effusion originates from infection of the pleura by Mycobacterium tuberculosis which is characterized by fluid accumulation and the presence of chronic inflammatory cells in the pleural cavity ${ }^{3}$. Tuberculous empyema occurs through the same mechanism but is often accompanied by more severe lung parenchymal lesions ${ }^{1}$. Empyema could be related to ineffective treatment as a result of anti-tuberculosis drugs (ATD) inadequately penetrating the thickened pleura due to fibrin deposits.

Hepatotoxicity is one of the adverse effects of ATD that could contribute to treatment interruption and may increase the risk of acquired resistance ${ }^{4}$. Some of the first-line ATD, isoniazid $(H)$, rifampicin $(R)$, and pyrazinamide $(Z)$ are metabolized in the liver and have the potential to cause hepatotoxicity ${ }^{5,6}$. Incidence of druginduced hepatotoxicity during TB treatment varies depending on the definition of hepatotoxicity used; the regimen used, the characteristics of cohort studies. Some studies reported a prevalence of hepatotoxicity as much as $2 \%-28 \%$ in patients receiving ATD therapy ${ }^{6,7}$. The criteria used to define hepatotoxicity are increasing alanine (ALT) or aspartate transaminase (AST) 3 times the upper limit of normal range with symptoms (abdominal pain, nausea, vomiting, unexplained fatigue or jaundice) attributable to liver injury or 5 times the upper limit of normal of ALT or AST without the symptoms of hepatotoxicity8.

\section{Case Presentation}

A 24 years-old woman came with the symptoms of cough and shortness of breath for two weeks before. There were decreased appetite, sweating, and weight loss. She has no history of previous pulmonary TB, asthma, liver disease, diabetes mellitus, and drug allergies. She was referred from a district hospital to the tertiary hospital after 10 days of hospitalization with the diagnosis of pulmonary $\mathrm{TB}$, right pneumothorax (Fig. 1.A), and drug-induced hepatitis due to ATD according to the WHO standard ${ }^{9}$. A chest X-ray during hospitalization in tertiary hospital revealed right hydropneumothorax (Fig. 1.B). The ATD was temporarily discontinued during hospitalizations. The patient was discharged when her condition improved and the intensive phase of standard 6-month treatment ATD (2HRZE/4HR) was reintroduced. After one week of taking the ATD, the patient complained of nausea, vomiting, decreased appetite, body weakness, jaundice and there was an increase in transaminases and bilirubin. Ethambutol (E) and streptomycin (S) were given as anti-tuberculosis therapy for two weeks until the liver function tests improved. Afterward, the patient was given isoniazid $(H)$, rifampicin (R), ethambutol (E) as the ATD regimen. Unfortunately, she complained of aggravating nausea and vomiting after one week of consuming those three ATD, along with an increase in transaminases level (Table 2). The ATD regimen (isoniazid, rifampicin, ethambutol) was stopped

Table 1. Patient examination data

\begin{tabular}{llll}
\hline Parameter & Result & Parameter & Result \\
\hline Leukocytes $(103 / \mathrm{uL})$ & 11.1 & Potassium $(\mathrm{mmol} / \mathrm{l})$ & 3.4 \\
Haemoglobin $(\mathrm{g} / \mathrm{dL})$ & 9.3 & Sodium $(\mathrm{mmol} / \mathrm{l})$ & 148 \\
Platelets $(103 / \mathrm{uL})$ & 343 & Chloride $(\mathrm{mmol} / \mathrm{l})$ & 104 \\
BUN $(\mathrm{mg} / \mathrm{dL})$ & 22 & Pleural fluid ADA $(\mathrm{U} / \mathrm{L})$ & 108 \\
Creatinine serum $(\mathrm{mg} / \mathrm{dL})$ & 1.07 & Procalcitonine $(\mathrm{ng} / \mathrm{mL})$ & 1.37 \\
Random glucose $(\mathrm{mg} / \mathrm{dL})$ & 73 & Aerobic culture of sputum & No isolate \\
Rapid HIV test & Non-reactive & Sputum smear of AFB & Positive \\
HBsAg & Non-reactive & Aerobic culture of pus & No isolate \\
CD4 count (cells $/ \mu \mathrm{l})$ & 234 & Sputum GenXpert MTB/RIF & M.Tb detected, Rifampicin \\
& & & resistance not detected \\
\hline
\end{tabular}

Note: BUN: Blood Urea Nitrogen; HIV: Human Immunodeficiency Virus; CD: Cluster Differentiation; ADA: Adenosine Deaminase; AFB: Acid-Fast Bacilli; HBsAg: Hepatitis B Surface Antigen

Journal of Pure and Applied Microbiology 
Table 2. Serial measurement of Liver Function Tests

\begin{tabular}{lccccccc}
\hline Parameter & $\begin{array}{c}\text { District } \\
\text { hospital }\end{array}$ & $\begin{array}{c}\text { Start of } \\
\text { tertiary } \\
\text { hospital } \\
\text { admission }\end{array}$ & $\begin{array}{c}\text { During } \\
\text { hospitalization } \\
\text { in a tertiary } \\
\text { hospital }\end{array}$ & $\begin{array}{c}\text { Before } \\
\text { initiation of } \\
\mathrm{H}, \mathrm{R}, \mathrm{E}\end{array}$ & $\begin{array}{c}\text { One } \\
\text { week } \\
\text { after H, } \\
\mathrm{R}, \mathrm{E} \\
\text { regiment }\end{array}$ & $\begin{array}{c}\text { Hospital re- } \\
\text { admission } \\
\text { for right } \\
\text { hemithorax } \\
\text { empyema }\end{array}$ & $\begin{array}{c}\text { Follow-up } \\
\text { during } \\
\text { hospitalization }\end{array}$ \\
\hline $\begin{array}{l}\text { AST (U/L) } \\
\text { ALT(U/L) }\end{array}$ & 286 & 716 & 24 & 26 & 726 & 33 & 23 \\
$\begin{array}{l}\text { Direct } \\
\text { bilirubin } \\
\text { (mg/dL) }\end{array}$ & 138 & 589 & 155 & 59 & 256 & 159 & 29 \\
$\begin{array}{l}\text { Total } \\
\text { bilirubin } \\
\text { (mg/dL) }\end{array}$ & -2.67 & 0.61 & 0.33 & 4.67 & 0.3 & - \\
$\begin{array}{l}\text { Serum } \\
\text { albumin } \\
\text { (g/dL) }\end{array}$ & 2.7 & 4.28 & 0.92 & 0.37 & 5.18 & 0.47 & - \\
\hline
\end{tabular}

Note: H: isoniazid; R: rifampicin; E: ethambutol

again temporarily and the patient was given curcumin as a hepatoprotective therapy. After the symptoms have subsided and the liver function tests returned to normal, isoniazid and ethambutol were given as anti-tuberculosis therapy. On a follow-up visit 2 weeks later, the patient did not complain of either shortness of breath or nausea and her vital signs were stable. However, asymmetrical chest movement with a decrease of vesicular sound on right hemithorax was identified on thoracic physical examination and the chest $X$-ray revealed homogeneous opacities on the right hemithorax (Fig. 1.C). Trial thoracentesis was done and pus was collected from the right hemithorax. A tube thoracostomy procedure was performed to drain pus from the right hemithorax and the patient was admitted to the TB isolation ward. The patient was hospitalized for 2 weeks, and when serum albumin and liver function tests improved, pyrazinamide $(Z)$ was added to the ATD regimen. The patient was discharged after empyema resolved and was given isoniazid, pyrazinamide, ethambutol as the final ATD regiment. Table 1 illustrates the biomarkers and microbiology data of the patient. This report has received patient's approval for publication.

\section{DISCUSSION}

Tuberculous pleural effusion develops after the rupture of subpleural caseous focus into the pleural cavity ${ }^{3}$. This theory is based on the finding of the caseous focus of tuberculosis in lung parenchyma adjacent to the pleura. The rupture of subpleural caseous focus into the pleural cavity causes the tuberculous protein to enter the pleural cavity and triggering hypersensitivity reactions. Delayed hypersensitivity reactions will increase pleural capillary permeability to protein. The increase of protein levels in pleural fluid stimulates a higher rate of pleural fluid formation. High protein content can obstruct the pleural lymphatic system and causing a decrease in fluid clearance rate. The increase of pleural fluid formation and the decrease of fluid removal will lead to the accumulation of pleural fluid $^{3,10}$. Tuberculous pleural effusion with severe lung parenchymal lesions can induce alveolar or bronchopleural fistula leading to secondary pneumothorax and empyema ${ }^{11}$. An identical process might occur in this case as this patient initially presented with pneumothorax and subsequent hydropneumothorax in the disease course. It was predicted that caseous focus in lung parenchyma entered the pleural cavity and promoted inflammation and fluid accumulation. Diagnostic criteria for tuberculous pleural effusion require confirmation of the presence of tuberculous bacilli in sputum, pleural fluid, pleural biopsy specimens, and isolation of Mycobacterium tuberculosis from culture. These standards 

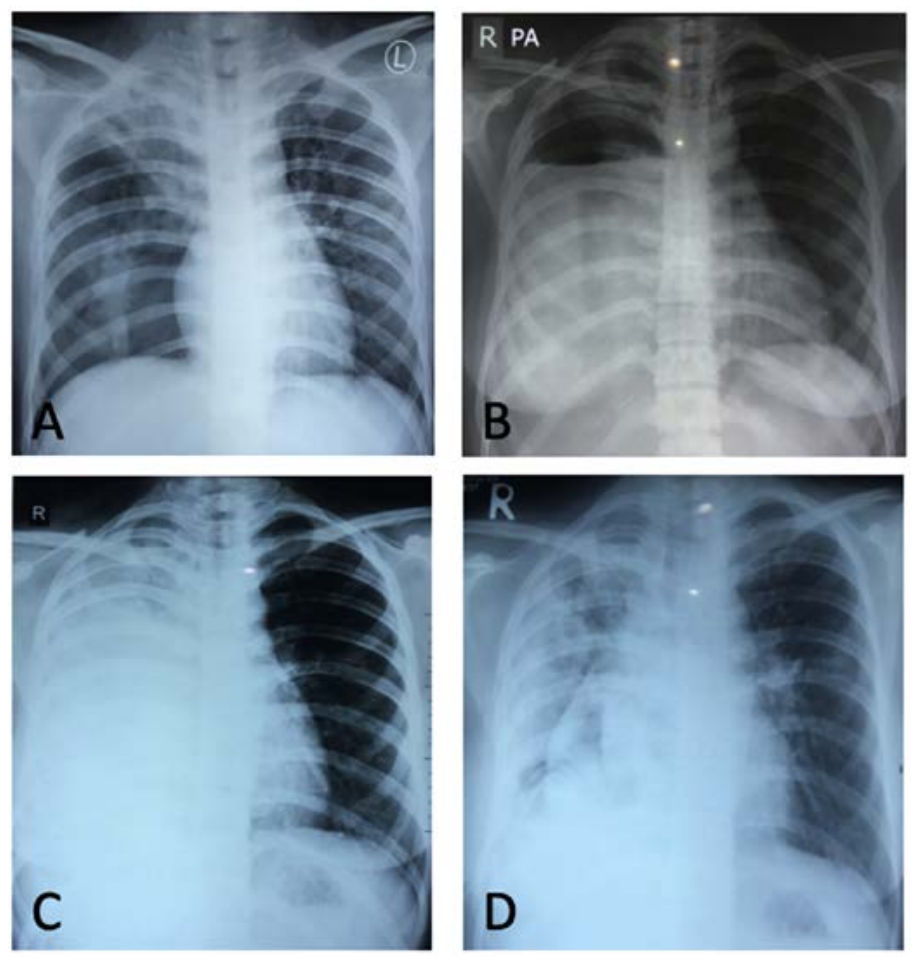

Fig. 1. (A). Chest X-Ray in a district hospital: right upper lobe fibroinfiltrate and pneumothorax; (B). Chest X-Ray in a tertiary hospital: air-fluid level in right hemithorax; $(C)$. Increase of right homogenous opacity in a follow-up chest X-Ray; D. A follow-up chest X-Ray after tube thoracostomy: collapse line with thickening of pleural peel, fibroinfiltrate on the right upper lobe.

elaborate on the diagnosis of tuberculous pleural effusion. Some biomarkers of pleural fluid can be used to support the diagnosis, such as adenosine deaminase (ADA) and interferon $\gamma$. The widely accepted cut-off value for pleural fluid ADA is $40 \mathrm{U} / \mathrm{L}$. The higher the level, the greater the likelihood of the patient has tuberculosis $(3,10)$. The diagnosis of tuberculous pleural effusion in this case report was based on the positive smear of acid-fast bacilli (AFB) of sputum, high level of pleural fluid ADA (104 U/L), mononucleardominant exudate pleural fluid, and negative aerobic culture of pleural fluid.

This 24 years-old woman was first diagnosed as pulmonary TB and was given standard 6-month treatment according to WHO recommendation ${ }^{9}$ in a district hospital. Hepatotoxicity developed after one week of taking intensive phase ATD (isoniazid, rifampicin, pyrazinamide, ethambutol). The exact mechanism of drug-induced liver injury (DILI) is not yet known. High levels of a drug in the serum ${ }^{6}$ and host factors such as age, gender, nutritional status, alcoholism, and concomitant infection are known risk factors for DILI. Despite the drug regimen and host factors were under control, the incidence of DILI remains unpredictable, indicating that genetic susceptibility can contribute to episodes of hepatotoxicity ${ }^{8}$. This patient had no previous history of drug allergy, however, her low albumin levels $(<3.5 \mathrm{~g} / \mathrm{dL})$ can be a risk factor for hepatotoxicity.

Inadequate treatment is a risk factor of ATD resistance $(12,13)$. In 1998, Bai et al. reported that 7 of 22 patients (38.9\%) were multi-drug resistant (MDR) in tuberculous empyema patients. History of irregular or incomplete pulmonary TB treatment were noted in 5 out of 7 patients (71.4\%) with MDR organisms ${ }^{14}$. Despite receiving inadequate TB therapy for two months due to the hepatotoxic episodes related to ATD, no resistance to rifampicin was identified in this patient's sputum geneXpert MTB/RIF.

Inappropriate treatment in tuberculous pleural effusion will produce partial healing or 
development of pulmonary/extra-pulmonary TB within a few years ${ }^{15}$. Casalini et al. reported a patient with tuberculous pleural effusion who did not receive ATD and later developed wrist tenosynovitis and pulmonary tuberculosis within the next three months ${ }^{16}$. Loh et al. reported 20 tuberculous pleural effusion cases with moderatelarge pleural effusion who received two months of daily isoniazid, rifampicin, pyrazinamide with or without ethambutol or streptomycin followed by four months of a daily or three times a week of isoniazid and rifampicin. Evaluation at 12-months after the completion of therapy demonstrated that 15 patients experienced complete resolution without requiring thoracentesis ${ }^{17}$. Bai et al. evaluated 597 pleural effusion cases, 307 of them were tuberculous pleural effusion cases, and 35 were of tuberculous empyemas. They also found that $78.9 \%$ of TB patients with a history of inappropriate therapy had empyema, supporting the theory that incomplete therapy is a risk factor of tuberculous empyema ${ }^{14}$. In this case report the patient, unfortunately, had inadequate TB therapy for two months as a consequence of hepatotoxicity episodes, and the tuberculous pleural effusion subsequently transformed into empyema.

\section{CONCLUSION}

A pulmonary TB patient with hydropneumothorax had episodes of druginduced liver injury. Hepatotoxicity due to ATD led to repeated regimen adjustment, resulting in inadequate therapy in the intensive phase, and the course of the disease resulted in pyopneumothorax.

\section{ACKNOWLEDGEMENTS}

We would like to express our sincere thanks to the Indonesia Tuberculosis International Meeting (INATIME) event which facilitated us to present this research on 5-7 April 2019 at Surabaya, Indonesia.

\section{CONFLICT OF INTEREST}

The authors declare that there is no conflict of interest.

\section{AUTHORS' CONTRIBUTION}

All authors contributed toward data analysis, drafting and revising the paper, gave final approval of the version to be published and agree to be accountable for all aspects of the work.

\section{FUNDING}

None.

\section{ETHICS STATEMENT}

All procedures performed in studies / case report were in accordance with the ethical standards of the Ethics Committee in Dr. Soetomo General Academic Hospital, Surabaya, Indonesia. The authors explains the aimed, benefits, and rights of the participant during the process of collecting data to the patient's guardian, if the participant agrees we ask the participant to fill out an informed consent sheet.

\section{DATA AVAILABILITY}

The dataset used and/or analyzed during the current study are available from corresponding author on reasonable request.

\section{REFERENCES}

1. Gayathri Devi HJ. Complication of pulmonary tuberculosis. 2014.

2. Kartaloglu Z, Okutan O, Isitmangil T, et al. Pyopneumothorax in Patients with Active Pulmonary Tuberculosis: An Analysis of 17 Cases without Intrapleural Fibrinolytic Treatment. Med Principles and Practice. 2006;15(1):33-38. https://doi. org/10.1159/000089383

3. Shaw JA, Diacon AH, Koegelenberg CFN. Tuberculous pleural effusion. Respirology. 2019;24(10):962-971. https://doi.org/10.1111/resp.13673

4. Song JH, Yoon S-Y, Park TY, et al. The clinical impact of drug-induced hepatotoxicity on anti-tuberculosis therapy: a case control study. Respiratory Research. 2019;20(1):283. https://doi.org/10.1186/s12931-0191256-y

5. Yee D, Valiquette C, Pelletier M, Parisien I, Rocher I, Menzies D. Incidence of serious side effects from firstline antituberculosis drugs among patients treated for active tuberculosis. Am Journal Respir Crit Care Med. 2003;167(11):1472-1477. https://doi.org/10.1164/ rccm.200206-6260C

6. Jeong I, Park J-S, Cho Y-J, et al. Drug-induced hepatotoxicity of anti-tuberculosis drugs and their serum levels. J Korean Med Sci. 2015;30(2):167-172. https://doi.org/10.3346/jkms.2015.30.2.167

7. Saukkonen JJ, Cohn DL, Jasmer RM, et al. An official ATS statement: hepatotoxicity of antituberculosis therapy. Am J Respir Crit Care Med. 2006;174(8):935952. https://doi.org/10.1164/rccm.200510-1666ST

8. Ramappa V, Aithal GP. Hepatotoxicity Related to Antituberculosis Drugs: Mechanisms and Management. J Clin Exp Hepatol. 2013;3(1):37-49. https://doi. 
org/10.1016/j.jceh.2012.12.001

9. WHO. Guidelines for treatment of drug-susceptible tuberculosis and patient care. 2017.

10. Shaw JA, Irusen EM, Diacon AH, Koegelenberg CF. Pleural tuberculosis: A concise clinical review. Clin Respir J. 2018;12(5):1779-1786. https://doi. org $/ 10.1111 /$ crj.12900

11. Kumar A, Asaf BB, Lingaraju VC, Yendamuri S, Pulle MV, Sood J. Thoracoscopic Decortication of Stage III Tuberculous Empyema is Effective and Safe in Selected Cases. Ann Thorac Surg. 2017;104(5):1688-1694. https://doi.org/10.1016/j.athoracsur.2017.06.038

12. van der Werf MJ, Langendam MW, Huitric E, Manissero D. Multidrug resistance after inappropriate tuberculosis treatment: a meta-analysis. Eur Respir J. 2012;39(6):1511-1519. https://doi. org/10.1183/09031936.00125711

13. Sharma M, Kumar D, Bohra GK, Meena DS, Bhambu SK. Study of the prevalence of Multidrug-Resistant
Pulmonary Tuberculosis (MDR-TB) in Western Rajasthan using line probe assay. J Family Med Prim Care. 2020;9(2):1093-1097. https://doi.org/10.4103/ jfmpc.jfmpc_916_19

14. Bai K-J, Wu I-H, Yu M-C, et al. Tuberculous empyema. Respirology. 1998;3(4):261-266. https://doi. org/10.1111/j.1440-1843.1998.tb00132.x

15. Cohen LA, Light RW. Tuberculous Pleural Effusion. Turk Thorac J. 2015;16(1):1-9. https://doi.org/10.5152/ ttd.2014.001

16. Casalini AG, Cusmano F, Sverzellati N, Mori PA, Majori $M$. An undiagnosed pleural effusion with surprising consequences. Respir Med Case Rep. 2017;22:53-56. https://doi.org/10.1016/j.rmcr.2017.05.007

17. Loh L, Lim B, Wan SY. Significant resolution of tuberculous pleural effusion on chemotherapy alone. J R Coll Physicians Edinb. 2010;40(2):100-1004. https:// doi.org/10.4997/JRCPE.2010.202 